\title{
UNITED NATIONS UNIVERSITY
}

\section{UNU-MERIT}

\section{Working Paper Series}

\#2008-018

\author{
Multinationals are Multicultural Units: \\ Some Indications from a Cross-Cultural Study
}

\section{Nantawan Noi Kwanjai \\ J Friso den Hertog}

March 2008 


\title{
Multinationals are Multicultural Units: Some Indications from a Cross-Cultural Study1
}

\author{
Nantawan Noi Kwanjai (kwanjai@merit.unu.edu) \\ J Friso den Hertog (F.denhertog@merit.unimaas.nl)
}

UNU-MERIT

\begin{abstract}
This paper makes a case for the value of looking at culture and multinationals from a management and organizational perspective because it is one which could direct greater attention towards culture as a significant factor in future investigation on multinational corporations. We attempt to illustrate that multinationals are fundamentally multicultural units in more ways than one.

This paper is based on selected materials from a qualitative study of culture and learning in organizations and management. The study investigated four selected Dutch firms in Thailand using evidences collected through observations and open-ended interviews. All evidences were analysed under grounded theory procedure. Parts of the evidences and theorization from the study are presented in this paper, which begins with two cultural riddles from one of the cases as a backdrop for subsequent discussions. Following the riddles is an abridge version of the key finding of the study - a grounded theory of cross-cultural intelligence. Then the two riddles are revisited, this time to illustrate how the proposed theory could illuminate an understanding of their covert meanings vis-à-vis culture and learning in multinationals. Last, we reinstate how our study and its theoretical and empirical findings can elucidate the central thesis that multinationals are essentially multicultural units.
\end{abstract}

Keywords: case study, culture, cultural intelligence, multinationals, Netherlands, Thailand JEL codes: F23, M16

\section{UNU-MERIT Working Papers \\ ISSN 1871-9872}

\author{
Copyright (C) 2008 UNITED NATIONS UNIVERSITY \\ Maastricht Economic and social Research and training centre on Innovation and Technology, \\ UNU-MERIT
}

\begin{abstract}
UNU-MERIT Working Papers intend to disseminate preliminary results of the research carried out at the institute to attract comments.
\end{abstract}

\footnotetext{
${ }^{1}$ This paper is under editorial review and to appear as a chapter in Duyters et al. (forthcoming). The study and this paper would have been impossible if not for the real ADT and its people who shared generously their experiences and insights, for which we can never repay but by sharing what we have learned with the wider community. We are also grateful to the reviewers of an earlier draft, whose critics, questions, comments and suggestions are intertwined with our labour in this delivery. Any remaining shortcomings are of course our own. For contact: kwanjai@merit.unu.edu.
} 


\section{Introduction}

Academic and policy discourse on multinational corporations has been prolific in both economic and management communities with substantial interdisciplinary influences, notably of the former on the latter. A side-effect of the dominance of economic thinking in the discourse on multinationals is a sore lack of attention on one fundamental element of multinational corporations, namely culture.

Culture, although not entirely ignored in economics, has never been given a rigorous attention (DiMaggio, 1990; Fernández, 2008; Guiso et al., 2006). At best culture is included as a variable but stripped down to its reductive surrogates. At worst, culture is set aside or put together with the residuals. Treatment of culture in economics, in brief, is still in elementary state. For this, management thinking may return the favour and inject an inspiring influence. This paper makes a case for the value of looking at culture and multinationals from a management and organizational perspective because it is one which could direct greater attention towards culture as a significant factor in future investigation on multinational corporations. This is because multinationals are fundamentally multicultural units in more ways than one, as we attempt to illustrate in this paper. Culture permeates many aspects of a multinational and to ignore, put aside, or downplay its role may render our understanding of multinational corporations inexcusably simplistic and critically incomplete.

This paper is based on selected materials from a qualitative study of culture and learning in organizations and management (Kwanjai, Forthcoming). The study investigated four selected Dutch firms in Thailand using evidences collected through observations and open-ended interviews. All evidences were analysed under grounded theory procedure (Corbin and Strauss, 1990; Glaser and Strauss, 1967; Locke, 2001; Strauss and Corbin, 1998) and the theorising effort yielded four extensive cases. A grounded theory of cultural intelligence, by the name of 'cross-cultural intelligence amidst webs of cultures,' became the key outcome of the study.

The paper begins with two cultural riddles from one of the cases in the study as a backdrop for subsequent discussions. Following the riddles is an abridge version of the key finding of the study - the aforementioned grounded theory of cross-cultural intelligence. Then the two riddles are revisited, this time to illustrate how the proposed theory could illuminate an understanding of their covert meanings vis-à-vis culture and learning in multinationals. Last, we reinstate how our study and its theoretical and empirical findings can elucidate the central thesis that multinationals are essentially multicultural units.

\section{Cultural riddles of deadline and mistake}

$\mathrm{ADT}^{2}$ is a Dutch company founded in the early 1980's by five engineering graduates of a well-known Dutch university, with an initial focus solely on design and development of data communication technologies. Until its entry into Thailand around 1997, the company outsourced all its production needs to third parties and concentrated mainly on its core competency in design and development.

\footnotetext{
${ }^{2}$ For anonymity, company and character names were replaced with fictitious ones. The stories, however, were based on real incidents and factual details were kept as accurate as possible.
} 
ADT's fully-owned subsidiary in Thailand came about as a by-product of an acquisition in 1997 of a local company to gain entry into retail market in Asia, where the acquired company already had a substantial market base. The acquired company came with a skeleton production plant in Rayong, Thailand, which ADT was initially not at all keen on keeping since its production so far had entirely been outsourced successfully. However, the Asian financial crisis and the resulting drastic devaluation of the Thai Bath that occurred at the same time as the acquisition made it incidentally very cost-effective to develop the plant. ADT decided to invest in the factory and experiment with having its own production.

As it turned out, ADT discovered that having its own production facility in-house carried many advantages, particularly the possibility for activities which could not be done via outsourcing, such as experimenting with new concepts, producing small specialised series or prototype products, and the like. Thus, by 2006, ADT's subsidiary in Thailand had developed to be the only in-house production facility of the budding multinational. Its operation was under the management of a Dutch Managing Director (MD), Khun Pim Kempster ${ }^{3}$, who was transferred from the headquarters. The MD has had a long history as a member of ADT top executives and was seen as someone who could provide the best channel to transfer corporate missions and management directives from the headquarters to the Thai subsidiary. He managed a team of about seven high-level technicians, all Thais, who were in charge of the factory operation that had about 100 local employees. Among the senior Thai staffs, Khun Maleewan Manasakul, a Thai female engineer, who was in charge of Production/Human Resource Management (HRM), was one who maintained the most interaction with Khun Pim and other senior Dutch executives.

Two other Dutch executives from the headquarters were in constant contact with the Thai plant. First, Corporate Vice President (VP) of Sales \& Marketing, Khun Joeri van Emmen, also handled sales and marketing in Thailand. Next, ADT top executive the Chief Executive Officer (CEO), Khun Kees van Dyke, kept a close eye on the Thai operations through constant communication with Khun Pim and Khun Joeri. He also paid regular visits to Thailand to oversee vital financial and management matters.

Khun Pim, the MD, was rather impressed with the Thai's willingness to serve and the different manner of daily living he met with as a high-ranked expatriate executive in Thailand. He gradually developed a deep affection for the Thai staffs at the plant. They were willing to serve, humble in their manner, yet strangely dignified. The 'dignified' humility was also appreciated by Khun Kees, the CEO, who found it to be a refreshing change from the overt brown-nosing manner he observed in some other countries he had been to. Yet, at times, the readiness to serve, or rather the eagerness to please, could create a strange tension.

\subsection{Dea dline: dead or a live?}

Take the routine case of setting up delivery schedule, for example. Khun Joeri always presented himself to the Thai plant as their 'biggest' customer. In a typical Dutch tradition, Khun Joeri believed that he only needed to make his wishes clear and then there should be no question about the delivery to fulfil those wishes. As a Production Manager/HRM, Khun Maleewan was directly responsible for scheduling the resources, physical as well as human,

\footnotetext{
${ }^{3}$ To give local flavour to the narration, all characters are addressed in Thai style as it was in real life, with the Thai "Khun" which is equivalent to Mr. or Mrs. in English, followed by the first name, except when first introduced. Character job titles follow what they were in real life.
} 
so that production could be done to meet delivery requirements, vis-à-vis quantity, quality, and time.

ADT itself served a customer-base that was very demanding and competed in a computerised technology market which changed so rapidly that stockpiling was not a viable solution. Put simply, the clients wanted the right products, at the right time, with the right quality. What this meant to Khun Joeri was that once a commitment was made for a delivery, it had to be delivered as and when committed. Delivery schedule for Khun Joeri was thus a deadline with the emphasis on dead. Khun Maleewan knew this of course and always tried to set production schedule so that it matched with Khun Joeri's expectation. For the factory, however, that commitment could be no more than a delivery schedule-as in intended date of completion, or a point of reference. Khun Pim on his part, could only trust that Khun Maleewan and her team would try their very best to keep to that point of reference.

Unfortunately, oftentimes, things did not go as scheduled and the delivery dates had to be rescheduled-sometimes more than once. At the factory, this was a matter of working harder to meet the new point of reference. But for Khun Joeri this could spell disaster. He needed to deal with anxious or, more often than not, disgruntling customers worldwide, since the Thai subsidiary had become ADT's main production facility. He might even need to take costly action to keep the deadline alive, such as having the shipment delivered by expensive air cargo across continents instead of cheaper sea freight. This dented the profit margin and did not reflect well on Sales \& Marketing. As it was, Khun Joeri and Khun Kees, the CEO, faced pressure from the clients everywhere and everyday to deliver on schedule. How could this pressure be felt just as acutely at the Thai factory, just so delivery schedule would translate into delivery deadline to them?

Khun Pim had experienced that kind of pressure before and so he certainly knew how it felt. Yet, everyday, he also witnessed how hard his staffs tried to serve and he learned that putting pressure was not really the Thai way of getting results. Khun Maleewan also felt the pressure. She knew when Khun Joeri, who was as blunt as blunt could be, said he wanted things delivered, it must be delivered and she tried her best to keep to the estimates. Still, she could only push the factory so far. The production was these people's jobs, yes, but it was not their lives. She knew that in Thailand people worked to live, not vice versa. She wished the schedules could be a tad more flexible as reference points, rather than deadlines that the Dutch made them out to be.

How could everyone be served and pleased at the same time? How could the delivery deadline and schedule be synchronized?

\subsection{Mistake: three strikes and you're out?}

Murphy's Law governed the ADT factory once in a while. That was to be expected. Nobody at ADT had the unrealistic expectation that mistakes would not be made. Still, mistakes could bring on complications that were beyond their simple direct consequences. The question was: how should one deal with mistakes?

ADT had a strict policy that Sales \& Marketing Department must be the only focal point of all communications with clients. This code of conduct was the key to keep ADT's tactical and strategic responses to market as solidified and competitive as possible. Khun Joeri, VP Sales 
\& Marketing, took this to be not only his main responsibility but also his crucial marketing tactic. He did not really mind dealing with the clients' concerns. It did not matter where in the company the concerns were related to, be it design and development, production, or after sale support. To deal with clients' requests and complaints was after all part of Khun Joeri's job. The information he got from such dealings could be used to improve future operation. In some cases, He could even use the situations to leverage his negotiation with the clients. If a client had any issue with ADT's products or services, Khun Joeri and his team were there to deal with it. All in a day's work.

But the clients sometimes did not really care to observe ADT internal code of conduct, like in the case of a Singaporean client who took it to himself to approach the factory directly regarding dissatisfaction with a particular shipment. To the client, this was the shortest route to having his concern addressed. The Thai staffs at the factory who received the complaint were very embarrassed and anxious. They knew that they should tell the client to go to Khun Joeri but they suspected that the client was reluctant to do so for a combination of reasons. The client was in Asia and it was more convenient to contact the Thai factory than the Dutch office. All that the client wanted was a direct, instant response he could get with a face-to-face meeting or simple phone call, without having to bother with time-zone difference or delayed e-mail communication. Moreover, most local clients preferred to deal with their local counterparts. To most Asians, it could be quite uncomfortable to approach and deal with the Dutch who were too far away and often too direct for them to cope with. To the Thai staffs, it was their obligation to please the client and rectify the shameful situation that arose out of their domain. They did not feel comfortable even to refer the problem to Khun Pim, the MD. In the end they tried their best to satisfy the client's request exactly as asked. After all, such direct dealings were not uncommon in most Thai business operations. Why involved Sales \& Marketing when it was actually the factory's fault? All's well that ends well.

Until Khun Joeri found out what happened. This made his job incredibly difficult. The factory was thus given a clear warning-a written announcement from the top boss, Khun Kees, the CEO, who was not amused with the incident either. 'Please next time, if and when the factory get any request from a client, whoever that is, refer the customer to Sales \& Marketing and do nothing else whatsoever until you hear from your biggest customer-VP of Sales \& Marketing.' End of Act One.

Act Two: a similar request from another local Asian client was addressed to the Thai plant. This followed again by a similar arrangement between the client and the Thai staffs. Another very stern warning was issued and made clear to all parties. This time it was specifically stated that whoever disobeyed this policy again would be simply asked to take leave. Three strikes and you're out. End of Act Two.

Khun Pim was not happy for Act Three to ever come about; he would feel greatly uncomfortable if he had to fire any of his Thai staffs. He knew it was a common practice back in the Netherlands for such a reprimand to be issued and take effect. Yet he felt ill at ease seeing that stern treatment applied to the Thai staffs, whom he now considered 'his people.' Although he realized they had repeatedly violated an important code of conduct, he also believed they were trying their best with the best intention and might not take the reprimand as it was intended by the headquarters. Khun Kees, the CEO, knew of course that the mistake was done with the best intention, which made it even more difficult for him, because the best intention did not translate into the best practice in this case. Something needed to be done to ensure that the best intention would equate the best practice. 
The intriguing questions remained. How could the best intention result in such unintended tension? Why was it that, for the same incident, the Thai focussed purely on the mistake at the production line as a shame to be rectified with honour while the Dutch were more concerned with the guilty disciplinary violation and its consequences? How could the best intention be aligned with the best practice? What exactly was the mistake, and was it a shame or guilt?

Before we attempt to decipher these two cultural riddles, a roadmap to the analysis must first be drawn.

\section{A grounded theory of cultural intelligence}

Culture is a concept that defies a unanimous definition. Numerous conceptualizations of culture span several decades and disciplines since its inauguration in anthropology in the 1960’s (Adler, 2002; Boyacigiller et al., 2004; Geertz, 1993; Groseschl and Doherty, 2000; Hofstede, 2001; House et al., 2004; Inglehart et al., 2004; Kroeber and Kluckhohn, 1963; Leung and Bond, 2004; Sackmann, 1991; Schneider and Barsoux, 2003; Schwartz and Sagiv, 1995; Trompenaars and Hampden-Turner, 1998). The conceptualization of culture in our grounded theory resonates with what previously put forward by Geertz (1993) and stands as yet one more variant for the meaning of culture. What emerged as the locus of culture in our theorizing are the sense-making process and the meanings that are the results of that process. Culture, under this locus, is thus a web of shared meanings that underlies two basic processes in social interaction: 1) cognitive process, which comprises sense-making and interpretation of all that a person encounters, be that material objects, social behaviours, or mental concepts, and 2) behavioural process, which comprises action, inaction and interaction, based on meanings given to the objects of that action, inaction or interaction. To wit, culture is a shared way of being and sense-making that is unique to a distinct group of people and can distinguish that group from others.

\subsection{A cultural onion model}

The cultural onion model is a widely accepted conceptualization of the internal dynamics of culture (Adler, 2002; Hofstede, 2001; Schneider and Barsoux, 2003). Although there are as many variations of the cultural onion as there are cultural theorists, all variants of the model, including ours, share the following fundamental implications. Culture manifests itself in diverse ways, shapes and forms, ranging from the most visible to the least fathomable. These many diverse manifestations of culture can be likened to the many layers of an onion. The outer layers are the more easily seen and comprehended components of culture, such as material objects, costumes, verbal and non-verbal languages, or architecture. The inner layers are the less visible facets, such as institutions or cognitive attributes. Most theorists would go on to state that these layers are all related to one another in a particular fashion. The most frequently theorised relation, again ours included, is that the inner layers are the ones that influence the outer layers, and the innermost, namely the cultural core, bears significant illumination to all cultural influences. Figure 1 below is a summary depiction of the particular cultural onion model theorised for the grounded theory in this study. 
Figure 1: A cultural onion model

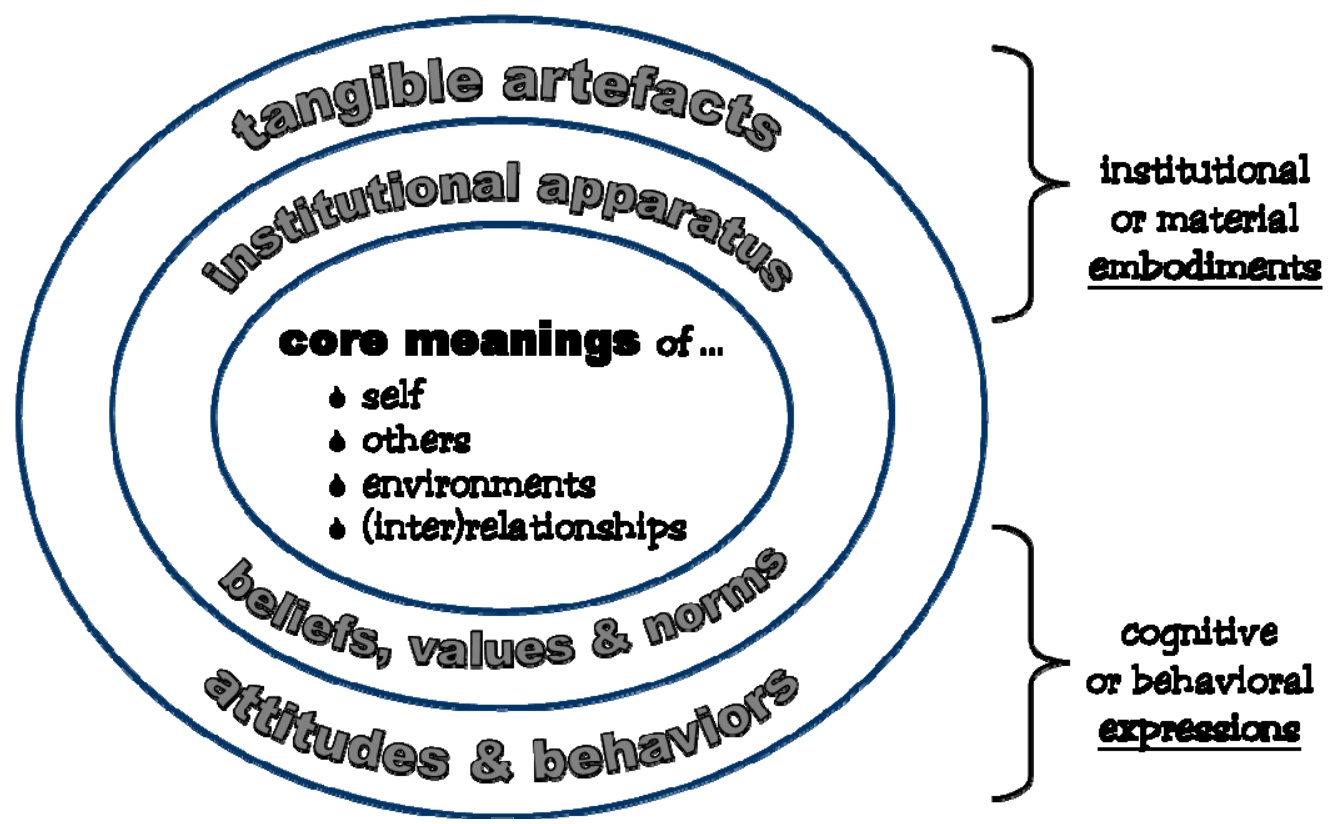

Source: Authors' theorization

\subsection{Cross-c ultural intelligence a midst webs of cultures}

A grounded theory of cross-cultural intelligence amidst webs of cultures ${ }^{4}$ is a theory of how a cultural unit (such as a person, group, organization, nation, and so on) operates in a crosscultural platform and as such could aid in analysis of cross-cultural phenomena.

The key property of any cultural unit is its cultural identity which comprises dynamic webs of cultures. A cultural unit, even an individual, usually belongs to or is made up of multiple cultures. The property of a cultural unit can thus be depicted as a cluster of many cultural onions. Most, if not all, cultural units will have many overlapping and oftentimes conflicting cultural layers from many cultural onions, thereby forming webs of cultures.

When a cultural unit operates in a cross-cultural platform, it then must function also amidst other webs of cultures. By definition, cross-cultural platform itself is also a cultural unit, with its own webs of cultures in force since cross-cultural platform designates a social condition that comprises people from at least two distinct cultures. As such, any real world crosscultural interaction is intractably complex, because it invariably involves multitude of competing meanings which are constantly in flux. To cope in such intractably, nondeterministic situation, a cultural unit has to exercise what we theorized as cross-cultural intelligence - the ability to manoeuvre the cultural webs effectively.

The complexity of webs of cultures calls for a specific strategy for which we coined the term 'cross-cultural heuristic.' Cross-cultural heuristic is the heart of cross-cultural intelligence-a

\footnotetext{
${ }^{4}$ The concept of cross-cultural intelligence (with the emphasis on 'cross') as developed in our theory bears a subtle, yet significant, distinction and relationship to a recently established concept of cultural intelligence (Ng and Earley, 2006; Thomas and Inkson, 2003; Triandis, 2006). Broadly speaking, the former is a specific subset of the latter. Please refer to Kwanjai and den Hertog (2008) for further details on this issue.
} 
simple strategy to deal with complex situation. By heuristic is meant a set of simple 'rules of thumb' which may not guaranteed optimal or even successful outcomes but promises possible satisfactory results at reasonable cost. Cross-cultural heuristic that has emerged in this study comprises a specific set of steps and tactics and is discussed in details elsewhere (Kwanjai and den Hertog, Work-in-progress).

\section{Understanding the cultural riddles of deadline and mistake}

\subsection{The case as a cultural unit}

The study and its theorizing centred on what transpired in the cases. Hence, the very central unit of analysis was a case, which was fundamentally a unique set of 'webs of cultures' in itself. Each of the cases in this study was a particular group of Dutch and Thai employees who worked together on a regular basis to serve a Dutch multinational that has an operation in Thailand. In each case, there exist many webs of cultures, with multitude of competing meanings.

For the cases in this study, it was the crossing of two distinct cultural units of the same level-national, that was the primary cross-cultural context: the crossing of Dutch and Thai cultures. This particular crossing of cultures thus became the exact spot where the theoretical lens zoomed in to expound upon. This section explores the underlying webs of meanings in these two cultures and identifies the potential competing meanings when the two cultures come into contact with each other.

\subsection{Core meanings: Dutch and Thai}

Based on the cultural onion model in Figure 1, Table 1 below summarises core meanings in the Dutch and Thai cultures as emerged from our study. Even at cursory glance, the contending nature of the two sets of meanings is interestingly evident. Not only do the two sets of meanings differ, they differ in quite a contending fashion. This is the first signal that the undercurrent of the two contending national cultures has a high potential to exert consequential influences, because it provides a rich ground for competing meanings.

\subsubsection{The meaning of 'self'}

First is the meaning of self, or in other words, the meaning of one's existence. In the Dutch culture, this is defined primarily by the individual him- or herself, meaning you are what you make of yourself. Not surprisingly, the Netherlands scored very high in Hofstede's individualism index - with an index of 80 and a rank way at the top 4-5, on par with Canada and only surpassed by the US, Australia and Great Britain (Hofstede, 2001: 500). Yet, the Dutch's view of self has its unique quality, in line with what has been theorised to be a major common Dutch trait: egalitarianism (van der Horst, 1996). As van der Horst inferred, the Dutch version of egalitarianism had its particular flavour, "[i]t advocates cultural individuality but not personal egoism” (van der Horst, 1996: 57). For the Dutch, the meaning of oneself is first and foremost a responsibility before it can turn into a right or privilege. You are responsible for your own significance but that does not mean that you are the only one that matters. Everybody is subject to this one responsibility and that is what makes for equality. You have to earn your meaning, in the Dutch eyes; you are not simply born deserving it. To repeat, you are what you make of yourself. 
Table 1: Core meanings, Dutch and Thai cultures

\begin{tabular}{|l|l|l|}
\hline Meaning of ... & \multicolumn{1}{|c|}{ DutcH } & \multicolumn{1}{c|}{ THAI } \\
\hline self & $\begin{array}{l}\text { is defined primarily by self. } \\
\rightarrow \text { You are what you make of yourself. }\end{array}$ & $\begin{array}{l}\text { is defined primarily by others. } \\
\rightarrow \text { You are what people make of you. }\end{array}$ \\
\hline others & $\begin{array}{l}\text { is defined by their acts in a situation, in } \\
\text { relation to what contributions those acts } \\
\text { make. }\end{array}$ & $\begin{array}{l}\text { is defined by their roles in a situation, in } \\
\text { relation to how they fulfil those roles. }\end{array}$ \\
\hline environment & $\begin{array}{l}\text { is a given, to be explored and exploited. } \\
\text { Nature: is functional and manageable. } \\
\text { Time: is valuable and must be used } \\
\text { efficiently. } \\
\text { Space: is scarce and must be used } \\
\text { efficiently. }\end{array}$ & $\begin{array}{l}\text { Nature: is sacred and animate. } \\
\text { Time: is a point of reference. }\end{array}$ \\
\hline (inter)relationship & $\begin{array}{l}\text { is defined by relative contributions to a } \\
\text { situation. }\end{array}$ & $\begin{array}{l}\text { is defined by relative roles in a } \\
\text { situation. }\end{array}$ \\
\hline
\end{tabular}

Source: Authors' theorization

The Thai, by contrast, tend to define the meaning of themselves based primarily on how they think other people make of their existence. It is not that they do not take their own ideas of themselves into account. They do, but only after and in relation to what they deem to be the ideas other people have of them. Not surprisingly, Thailand scored in the opposite direction to the Netherlands in Hofstede's individualism index - an index of 20 and ranked way towards the bottom half at 39-41. Many analyses of the Thai culture indeed unanimously classified it as a 'collectivist' society, where collective thinking exerts decisive forces on individuals (Atmiyanandana and Lawler, 2004; Holmes and Tangtongtavy, 1997; Komin, 1991; Mulder, 2000; Redmond, 2002). Komin's interpretation of the Thai ego-orientation described exactly how the Thai ego was shaped in a collectively oriented way, because by 'ego oriented' she meant highly conscious of self-image (Komin, 1991). As such, for the Thai, self or ego is what is out there in the open, defined and revealed by how others treat and define you. You are what people make of you, in a nutshell.

Holmes \& Tangtongtavy gave an insightful view of how the Thai would behave based on other people's view. They theorised on the exact nature of 'others' that the Thai take into account under the framework of 'the three circles of Thailand' (Holmes and Tangtongtavy, 1997: 39-44), which basically classified the three spheres of social circles from the most intimate one-the family circle, to the non-family but important one-the cautious circle, to the negligible one-the selfish circle. They elaborated on how Thais would behave differently when operated in each of these circles. Their observation sheds interesting lights on how the Thai define the meaning of themselves. How a typical Thai takes into account what other people think of him- or herself, depends very much on from which of these circles those others belong to. How a family member, which also includes someone you consider as virtually your family, makes of you is meaningful but can be taken for granted. Those others from the cautious circle, however, are ones whose notion of you must be cautiously cultivated and harvested. These are the people you interact with on a social or formal basis, at work, 
social functions, and so on. How the views of these others would contribute to the meaning of your existence, in turn, depends on who they are, to you. How your boss sees you, for example, would contribute greatly to who you are at work. If he or she thinks well of you, then you are significant in your work function. The same can be said of your teachers, friends, colleagues and so on. Finally, the negligible others are those from the selfish circle, the circle where you can totally define your own ego without paying much attention to the views of these insignificant others. These are people who have no lasting influences on your life and as such, how they make of you have no influence on the meaning of your existence in the Thai's view.

\subsubsection{The meaning of 'others'}

The meanings of others in the Dutch and Thai cultures are logically related to the meanings of self. Generally, how the Dutch and Thai give meanings to others is a kind of mirror images of how they give meanings to themselves, although the process has its own slant and emphasis.

The Dutch define the meanings of others by their acts in a situation and in relation to what contributions those acts make to the situation. In a way, this is also rooted in the egalitarian spirit of the Dutch culture-each person is judged based on how he or she is and acts, individually. It also relates very much to the Dutch utilitarianism as identified by van der Horst (1996). For a Dutch, those whose acts contribute positively to a situation are one whose existence bears valuable meaning. The opposite is of course true when their acts contribute negatively to a situation. Thus the Dutch take people based on what they do and the contributions they make.

The Thai, on the other hand, are first and foremost concerned with what role a person has and how he or she fulfils that role. The meaning of other people is first defined by looking at who they are in a situation. The role of each person in a situation has first to be established before one knows how to address and interact with every individual one meets. There is, however, more than a simple rule of hierarchy in the Thai webs of meanings. Again, the framework of the three circles of Thailand provides an elucidation. The Thai see meanings in others, first and foremost, based on which circle those others belong to. Within each circle, there are a set of roles, each of which has its own specific rank, status, behaviour, contribution, and so on, or in brief, the total meaning of a person in that role. What role a person takes in a particular situation is then based on a combination of diverse factors-initial birth condition, age, gender, education, social status, achievement, responsibility, task, and so forth.

Once roles are established in a situation, the Thai would then see others based on how they fulfil their particular roles. Certain expectations of character and behaviour are always associated with each role. In general, the higher in rank a role is, the more superior quality is expected. Role definition is then set against role fulfilling, and when the two do not correlate in a person, the meaning of that person diminishes significantly. In the work place, for example, a boss is expected to be superior in all aspects of character and behaviour. He or she is supposed to know best, act kindly but decisively, make good decisions, lead with confidence, take responsibility, be morally and ethically sound and so forth. If a boss does not fulfil these expectations, a Thai subordinate tends to think less of him or her. A subordinate, by comparison, has a different set of expectations to fulfil. In general, a subordinate does not need to know best but must follow order well and be loyal to the boss without a speck of doubt. Loyalty usually implies defending the boss's honour, or face, as if it were one's own. 


\subsubsection{The meaning of 'environment'}

The Dutch and the Thai look at the environment, again, in a starkly contending way. For the Dutch, the environment is simply a 'given' whose value must be explored and exploited. By explore is meant a practical survey to evaluate the situation and by exploit is meant to make the best possible use of what is given. This applies to all aspects of environment. Thus to the Dutch, natural environment serves a functional purpose and must be managed to the best of its potential. The famous Dutch dykes and other ingenious ways to make use of land and water are testimonials to this spirit and often used to characterise the Dutch utilitarian view of their physical environment (Hampden-Turner and Trompenaars, 1993; van der Horst, 1996). The Dutch treat abstract environment in the same fashion. Time and space are truly scarce resources to the Dutch, serve functional purposes, and must be managed and used efficiently. Punctuality is a virtue in the Dutch culture because time is precious and must be well observed. The 'deadline' episode at ADT is a classic illustration of how the Dutch view time, and how that view can cross with meaning of time in other cultures, as will be duly elaborated on.

The Thai, by contrast, take environment as a gift, to be thankful for and revered. Natural environment is deemed sacred and animate; there are gods for all various natural artefactsrivers, mountains, valleys, forests, rain, drought, the sun, moon, star, sky, and so on. Countless rituals are associated with how the Thai look at natural environments not as physical objects but animated entities. Abstract environment is regarded by the Thai in a similar fashion. Time is regarded as a part of life, it is a mere point of reference and its meaning is relative. As Klausner observed: 'the Thai are adverse to being slaves to the clock' (Klausner, 1993: 334). Time, in other words, is part of what transpire, and not a dictate of them. In fact, the Thai tend to regard haste as something that could lead to undesirable results, such as mistakes and accidents. No wonder, at ADT deadlines for the Thai employees were neither definite nor critical; they were mainly points of reference. As for space, the Thai regarded this as part of nature and so their view of space is similar to how they view natural environment. The Thai concept of space is very similar to the Chinese concept of 'feng shui' even though they do not subscribe to meticulous practices as do the Chinese.

\subsubsection{The meaning of '(inter)relationship'}

The meanings of (inter)relationship in the Dutch and the Thai cultures follow fairly straightforwardly from how they view self, others and environment. Put simply, for the Dutch, (inter)relationship between and among those three basic entities are based primarily on the relative contributions of each of those entities to a situation. The Thai, however, define (inter)relationship first and foremost based on the relative roles of those entities and how the roles are fulfilled. Since relationship and interrelationship are diverse and situational dependent, the discussion on this issue can only be kept at a broad level unless given specific contextual references.

\subsection{Interpreting the cultural riddles}

The above set of potentially contending core meanings in the Dutch and the Thai cultures gives rise to great possibilities that the two cultures will give meanings to many concepts, entities or acts, not just in different manners but more so in a divergent fashion and hence most likely to bear significant force in the crossing of the two cultures. It must be pointed out 
that the term 'significant force' emphasizes only the issue of strength and does not carry with it any judgmental insinuation. It suggests simply that the starkly contending meanings have a great potential to define the nature of the crossing of these two cultures, but does not claim to predict any specific property of that nature-good or bad, positive or negative. Opposites can attract as well as repel, and that is exactly the case with cross-cultural cultural contention.

\subsubsection{Dea dline: dead or a live?}

The riddle on delivery schedule v. delivery deadline is a web of contending meanings at many levels. At the very core are the contending meanings of time. For the Dutch, time is precious and schedule is a sacred contract; for the Thai, time should not be allowed to dictate but only to provide a point of reference. As such, for the Dutch, particularly Khun Joeri, the VP of Sales \& Marketing, delivery timetable was a guarantee of commitment. It designated what he guaranteed to delivery to customers, which equated to what the production line guaranteed to deliver to him. It was a deadline, meaning failure to fulfil this commitment would result in a fatal consequence. In the Thai culture, as time is usually seen as something one should take command of and not be subject to, Thais tend not take appointment too seriously. It is only a point of reference, something that you set up so you have an idea of your target. Not meeting an appointment means no more than that either the target is wrongly set or something else happens that has not been included in the estimation. That means a new target can be set and life goes on, no fatality needed.

The deadline episode also illustrates influences of a few other contending meanings: valuation, lifestyle, work and play, and privacy. For brevity's sake these manifestations are not elaborated further.

\subsubsection{Mistake: guilt or shame?}

The episode concerning mistake at ADT provides a good illustration of how the Thai and the Dutch see mistake so differently in many aspects. Fundamentally, it illustrates how the different ways the Dutch and Thai give meaning to themselves could influence their views of mistake. For the Thai employees, the company and their bosses were 'family' and the mistake was seen as a loss of face to the outer cautious circle, the client, whom they needed to be most careful with. Their reasoning could be as follows. The customers must always think well of you and your boss, else you would lose your face, and your business. How the bosses thought of you and how you acted in this case was an internal affair that could be easily resolved within the family. Thus, it was more important to take quick action to remedy the customer's negative view. More, this interpretation also brings out the complexity of 'webs of cultures' since it illustrates how there can be no deterministic rule of when a particular cultural force will be the trigger of a particular action. In this case, the force of the familial role as part of the company was stronger than the force of the role as an obedient employee, because Thais are most concerned with face when dealing with the cautious circle. The boss was part of the family circle, whose collective face was preeminent to any violation of internal agreement.

Then, there were at least two other aspects to the meanings of mistake: what mistake signifies v. what is identified as a mistake. The Thai tend to look at mistake with apprehension. This has to do with the abhorrence of losing face. To most typical Thais, it is very important to be perceived well by the two important circles of others in the community, particularly the cautious circle. And to be perceived well is achieved mostly by fronting respectable, flawless appearances, reinforced by the eagerness to please others. In reverse, anything that signifies a 
weakness, failure or inferiority is to be avoided, covered up, or readily rectified. Mistake signifies negative quality and is a cause for shame. While Thais are shameful of mistake, the Dutch tend to take it simply as a sign of inefficiency or incorrect choice. To a typical Dutch, one learns from one's mistake and moves on. To learn from mistake, one first needs to acknowledge it, or have it pointed out in the face. As such, to make the same mistake repeatedly in the Dutch eyes is a sign of either inexcusable ignorance or misguided stubbornness.

The above interpretation may explain partly why the Thai staffs acted the way they did when confronted with a client's complaint, and why the Dutch were not amused at the repeated violation of the company policy. It may also explain why there was a mismatch of identification of what exactly was 'the' mistake. The Thai factory felt responsible for having delivered 'bad' products and at the same time when confronted by the client, identified themselves as part of the company. They must have felt doubly shameful: at having produced bad products and embarrassed on behalf of the company. While the Thai looked externally, the Dutch were more concerned with the internal implication of the mistake. Khun Kees and Khun Joeri were much less concerned with the defect in shipment than with the outright violation of the company's key policy. To them as executives, the consequences of the production mistake were at operational level, while violation of code of conduct struck at company's strategic and tactical cord. The incident thus illustrated a rather tangled web of mismatched meanings of mistake.

\subsection{So what?}

It must be emphasized that the above analyses are but our interpretations of the story. We do not claim to deliver the impossible task of having a complete or absolute understanding of it. Our intention is to illustrate how the webs of meanings based on cultural interpretation could give plausible explanation to what can influence people to act the way they do in real world cross-cultural encounters. Also, it is not our intention to prescribe a cultural determinist view that culture is the only force in social phenomena. We intend to point out only that culture is one of the significant forces. What is important is not to see culture everywhere, but rather to see it where it matters.

And that is when cross-cultural heuristic comes into play. So far we may have given an impression that the complexity of webs of cultures are beyond comprehension and solution or resolution. That is far from the case. We intentionally did not go beyond deciphering the possible competing meanings in the case. We did not conclude which meaning was most effective, because, as our study has revealed, such conclusion is highly situational and the key to find a solution or resolution to the complexity of cross-cultural condition and its multitudes of competing meanings lies in an understanding and practicing of the cross-cultural heuristic. This, however, is a topic that is beyond the scope of this paper and can be referred to elsewhere (Kwanjai and den Hertog, Work-in-progress).

\section{Culture and multinational comorations}

Under the view of the proposed grounded theory on cross-cultural intelligence, it can be argued why multinationals are multicultural units. By its definition, multinational corporations are cultural units made up of more than one cultures, that is, more than one 'national' cultures, for starters. In most cases, there are more than one 'national' cultural 
forces within multinationals, since they must function in a variety of cultural webs of international markets, employ employees from a variety of countries, work with supplychains from diverse nations, and so on so forth. More, 'national' culture is but one possible web within multinational corporations. As the concept of webs of cultures would suggest, multinational corporations, viewed from our proposed theory, are complex webs of cultures operating in yet other webs of cultures. It should not be difficult to imagine the many possible groups and layers of cultures - clique, team, department, profession and so on, that must be spinning their webs within one single multinational corporation.

This is our simple assertion of a very complex issue that carries one key implication: multitude of cultural forces and their competing meanings form a potential influencing factor underlying multinational corporations. What happen with and within multinationals are essentially a form of cross-cultural interface in more ways than one. As such, a genuine understanding of the dynamics of these cultural forces, their competing meanings, and the cross-cultural interactions that they may be driving must be one of the indispensible insights needed in the study of multinational corporations. To date, as observed in the introduction, this has yet not been the case in the economic discourse of multinationals. It is hoped that the work on cross-cultural management, where culture has received a more rigorous attention during the past half century, together with the implications of the proposed theory, would inspire some in the economic community to put culture at the forefront of economic investigation of multinational corporations. A set of elementary observations on how this could develop serves as our conclusion.

\section{Conclusion}

As culture has received relatively little attention in economic study of multinational corporations, the first challenge is to concentrate the effort on driving home the significance of culture in research on multinationals. A conviction that multinationals are multicultural units with complex webs of cultures as their cultural identity as well as their operating context may be one instrument in such effort. Theoretically, economics could benefit from the advances in the conceptualization of culture accomplished by the management community and make a jump start in further delving into relating culture to economic issues in multinationals. The question of how cultural dimensions relate to the many economic aspects of a multinational, such as growth, profit, mode of entry, or innovation, could be investigated based on the success of many management studies that relate culture to management topics. Last, and probably most importantly, economic study of multinational corporations could benefit from the crucial lesson learned in the management community regarding culture, namely, that this is one theme of research which demands diversity of views, methods, and cultures (Boyacigiller et al., 2004; Usunier, 1998). As such, it may be crucial for the economic community to include in their study of culture and multinationals paradigms of inquiry and methodologies that are not the mainstream in economics. For example, nonpositivist perspective and qualitative approach should be encouraged, a prospect that admittedly may not be easily accomplished given the established inclination in economic study. That may yet be the ultimate challenge for economic research that seek to investigate culture and multinationals. 


\section{References}

Adler, N. J. (2002), International Dimensions of Organizational Behavior (4th ed.). Cincinnati, Ohio: South-Western.

Atmiyanandana, V.and Lawler, J. (2004), 'Introduction: Culture and Management in Thailand', in M. Warner (Ed.), Culture and Management in Asia, 229-248, London: Routledge.

Boyacigiller, N. A., Kleinberg, M. J., Phillips, M. E. and Sackmann, S. A. (2004), 'Conceptualizing Culture: Elucidating the Streams of Research in International CrossCultural Management', in B. J. Punnett and O. Shenkar (Eds.), Handbook for International Management Research, 2nd ed., 99-167, Ann Arbor: The University of Michigan Press.

Corbin, J. and Strauss, A. L. (1990), 'Grounded Theory Research: Procedures, Canons, and Evaluative Criteria’, Qualitative Sociology, 13(1), 3-21.

DiMaggio, P. J. (1990), 'Cultural Aspects of Economic Organization and Behavior', in R. Friedland and A. F. Robertson (Eds.), Beyond the Marketplace: Rethinking Economy and Society, 113-136, Chicago: Aldine Publishing Company.

Duysters, G., Dolfsma, W.andCosta, I (Eds.), (forthcoming), Multinationals and Emerging Economies: The Quest for Innovation and Sustainability, London: Edward Elgar Publishing.

Fernández, R. (2008), 'Culture and Economics', In S. DurlaufandL. Blume (Eds.), The New Palgrave Dictionary of Economics, 2nd ed., Hampshire: Palgrave Macmillan.

Geertz, C. (1993), The Interpretation of Cultures: Selected Essays, London: Fontana Press.

Glaser, B. G. and Strauss, A. L. (1967), The Discovery of Grounded Theory, Chicago: Aldine Publishing Company.

Groseschl, S. and Doherty, L. (2000), 'Conceptualising Culture', Cross Cultural Management, 7(4), 12-17.

Guiso, L., Sapienza, P. and Zingales, L. (2006), 'Does Culture Affect Economic Outcomes?', Journal of Economic Perspectives, 20, 23-48.

Hampden-Turner, C. and Trompenaars, F. (1993), 'Self-Constructed Lands: The Dutch as God's Apprentice', in C. Hampden-Turner and F. Trompenaars (Eds.), The Seven Cultures of Capitalism: Value Systems for Creating Wealth in the US, Britain, Japan, Germany, France, Sweden and the Netherlands, 261-292, London: Doubleday.

Hofstede, G. (2001), Culture's Consequences: Comparing Values, Behaviors, Institutions, and Organizations across Nations (2nd ed.), London: Sage Publications.

Holmes, H. and Tangtongtavy, S. (1997). Working with the Thais, Bangkok: White Lotus. 
House, b. R. J., Hanges, P. J., Javidan, M., Dorfman, P. W. and Gupta, V. (Eds.) (2004), Culture, Leadership, and Organizations: The Globe Study of 62 Societies, London: Sage Publications.

Inglehart, R., Basanez, M., Diez-Medrano, J., Halman, L. and Luijkx, R. (Eds.) (2004), Human Beliefs and Values: A Cross-Cultural Sourcebook Based on the 1999-2002 Values Surveys,_Mexico: Siglo Veintuno Editores.

Klausner, W. J. (1993), Reflections on Thai Culture (4th ed.), Bangkok: Siam Society.

Komin, S. (1991), Psychology of the Thai People: Values and Behavioral Patterns, Bangkok: National Institute of Development Administration (NIDA).

Kroeber, A. L. and Kluckhohn, C. (1963), Culture: A Critical Review af Concepts and Definitions (New ed.), New York: Random House.

Kwanjai, N. N. and den Hertog, J. F. (2008), 'Cultural intelligence: A qualitative angle', Paper presented at the 24th European Group for Organizational Studies (EGOS) Colloquium, Amsterdam.

Kwanjai, N. N. (Forthcoming), Cross-Cultural Intelligence amidst Webs of Cultures: A Tale of the UnDutchables in the Land of 1001 Smiles, Maastricht, the Netherlands: Maastricht University.

Kwanjai, N. N. and den Hertog, J. F. (Working paper). 'Cross-Cultural Heuristic: at the Heart of Successful Cultural Intelligence'.

Leung, K. and Bond, M. H. (2004), 'Social Axioms: A Model of Social Beliefs in MultiCultural Perspective’, in M. P. Zanna (Ed.), Advances in Experimental Social. Psychology, 36, 119-197, San Diego, CA: Elsevier Academic Press.

Locke, K. (2001), Grounded Theory in Management Research. London: Sage Publications.

Mulder, N. (2000), Inside Thai Society: Religion, Everyday Life, Change, Chiang Mai: Silkworm Books.

Ng, K.-Y. and Earley, P. C. (2006), 'Culture + Intelligence: Old Constructs, New Frontiers', Group Organization Management, 31(1), 4-19.

Redmond, M. (2002), Wondering into Thai Culture, Bangkok: Redmondian Insight Enterprises.

Sackmann, S. A. (1991), Cultural Knowledge in Organizations: Exploring the Collective Mind, Newbury Park: Sage Publications.

Schneider, S. C. and Barsoux, J.-L. (2003), Managing Across Cultures (2nd ed.), New York: Prentice Hall.

Schwartz, S. H. and Sagiv, L. (1995), 'Identifying Culture-Specifics in the Content and Structure of Values’, Journal of Cross-Cultural Psychology, 26, 92-116. 
Strauss, A. L. and Corbin, J. (1998), Basics of Qualitative Research: Techniques and Procedures for Developing Grounded Theory (2nd ed.), Thousand Oaks, CA: Sage Publications.

Thomas, D. C. and Inkson, K. (2003), Cultural intelligence: People Skills for Global Business, San Francisco: Berrett-Koehler Publishers, Inc.

Triandis, H. C. (2006), 'Cultural Intelligence in Organizations', Group Organization Management, 31(1), 20-26.

Trompenaars, F. and Hampden-Turner, C. (1998), Riding the Waves of Culture: Understanding Diversity in Global Business (2nd ed.), New York: McGraw-Hill.

Usunier, J.-C. (1998), International and Cross-Cultural Management Research, London: Sage Publications.

van der Horst, H. (1996), The_Low Sky: Understanding the Dutch, Schiedam: Scriptum Books. 


\section{The UNU-MERIT WORKING Paper Series}

2008-01 Title to be announced by Luc Soete

2008-02 Reframing technical change: Livestock Fodder Scarcity Revisited as Innovation Capacity Scarcity. Part 1. A Review of Historical and Recent Experiences by Andy Hall, Rasheed Sulaiman V., Mona Dhamankar, Peter Bezkorowajnyj \& Leela Prasad

2008-03 Reframing technical change: Livestock Fodder Scarcity Revisited as Innovation Capacity Scarcity. Part 2. A Framework for Analysis by Andy Hall, Rasheed Sulaiman, V. and Peter Bezkorowajnyj

2008-04 Reframing technical change: Livestock Fodder Scarcity Revisited as Innovation Capacity Scarcity.Part 3. Tools for Diagnosis and Institutional Change in Innovation Systems by Andy Hall, Rasheed Sulaiman and Peter Bezkorowajnyj

2008-05 Is Inter-Firm Labor Mobility a Channel of Knowledge Spillovers? Evidence from a Linked Employer-Employee Panel by Mika Maliranta, Pierre Mohnen \& Petri Rouvinen

2008-06 Financial Constraints and Other Obstacles:Are they a Threat to Innovation Activity? By P. Mohnen, F.C. Palm, S. Schim van der Loeff and A. Tiwari

2008-07 Knowledge-based productivity in 'low-tech' industries: evidence from firms in developing countries by Micheline Goedhuys, Norbert Janz and Pierre Mohnen

2008-08 The Voyage of the Beagle in Innovation Systems Land.Explorations on Sectors, Innovation, Heterogeneity and Selection by Martin Srholec \& Bart Verspagen

2008-09 Crafting Firm Competencies to Improve Innovative Performance by Boris Lokshin, Anita van Gils \& Eva Bauer

2008-10 The Economics and Psychology of Personality Traits by Lex Borghans, Angela Lee Duckworth, James J. Heckman \& Bas ter Weel

2008-11 Embedding Research in Society: Development Assistance Options for Supporting Agricultural Innovation in a Global Knowledge Economy by Andy Hall

2008-12 Playing in Invisible Markets: Innovations in the Market for Toilets to Harness the Economic Power of the Poor by Shyama V. Ramani

2008-13 Explaining Success and Failure in Development by Adam Szirmai

2008-14 Running The Marathon by William Cowan, Robin Cowan and Patrick Llerena

2008-15 Productivity effects of innovation, stress and social relations by Rifka Weehuizen, Bulat Sanditov and Robin Cowan

2008-16 Entrepreneurship and Innovation Strategies in ICT SMEs in Enlarged Europe (EU25) by Kaushalesh Lal and Theo Dunnewijk

2008-17 Knowledge Transfers between Canadian Business Enterprises and Universities: Does Distance Matter? By Julio M. Rosa \& Pierre Mohnen

2008-18 Multinationals are Multicultural Units: Some Indications from a Cross-Cultural Study by Nantawan Noi Kwanjai \& J. Friso den Hertog 
